Çukurova Üniversitesi Mühendislik Mimarlık Fakültesi Dergisi, 31(2), ss. 391-400, Aralık 2016

Çukurova University Journal of the Faculty of Engineering and Architecture, 31(2), pp. 391-400, December 2016

\title{
Tuz Gradyentli Bölgenin Güneş Havuzunun Performansı Üzerine Etkisi
}

\author{
Mehmet KARAKILÇIK ${ }^{* 1}$ \\ ${ }^{1}$ Çukurova Üniversitesi, Fen Edebiyat Fakültesi, Fizik Bölümü, Adana
}

Geliş tarihi: 12.06.2016 Kabul tarihi: 23.11.2016

$\ddot{\mathbf{O} z}$

Bu çalışmada, yüzey alanı $4 \mathrm{~m}^{2}$, derinliği $1,5 \mathrm{~m}$ ve yan duvarları yalıtımlı bir güneş havuzunun tuz gradyentli (eğimli) bölgesinin havuzun 1sı performansı üzerindeki etkisi incelenmiştir. Tuz eğimli bölge 1S1 depolama bölgesinden itibaren yukarıya doğru azalan yoğunluklarda $10 \mathrm{~cm}$ kalınlığında 6 farklı yoğunluklu tuzlu su tabakasının üst üste yı̆̆ılmasıyla oluşturulan saydam ve konveksiyonsuz bir bölgedir. Konveksiyonsuz bölgeyi oluşturan tuzlu tabakalarının saydamlığı kadar kalınlığı ve yoğunluk dağılımları da havuzun 1S1 performansı üzerinde etkili önemli parametrelerdir. Bu etkinin belirlenmesi için, tabakaların sıcaklığa ve yoğunluğa bağlı olarak değişen öz ısıları yılın farklı ayları için hesaplanmıştır. Bu parametrelere göre, havuzun iç bölgelerinde depolanan aylık ortalama ısı dağılım oranları belirlenmeye çalışılmışıtır. Sonuç olarak, 1sı depolama bölgesinin aylık ortalama 1sı depolama oranları, Ocak, Mayıs ve Ağustos ayları için sırasıyla, 11,43 MJ, 212,42 MJ ve 320,95 MJ olarak belirlenmiştir.

Anahtar Kelimeler: Tuz gradyenti, Güneş havuzu, Güneş enerjisi, Isı depolama, Isı transferi

\section{The Effect on Performance of the Salt Gradient Zone of the Solar Pond}

\begin{abstract}
In this study, a solar pond of surface area $4 \mathrm{~m}^{2}$ and depth $1.5 \mathrm{~m}$ is considered and the effect of the salt gradient zone with insulated side walls on the heat performance of the solar pond was investigated. Salt gradient zone is transparent and non-convective zone which was formed by stacking of 6 different density brine layers each of $10 \mathrm{~cm}$ thickness in decreasing intensity upwards from the heat storage region. The non-convective zone's thickness and density distributions as much as the transparency of brine layers are important parameters acting on the thermal performance of the pond. To determine this effect, the variation of specific heat as a function of temperature and density of the layer is calculated for various months. Using these parameters, the average monthly rates of heat distribution that is stored in the inner region of the solar pond were determined. As a result, the average monthly rates of heat storage are found to be 11.43 MJ for January, 212.42 MJ for May and 320.95 MJ for August.
\end{abstract}

Keywords: Salt gradient, Solar pond, Solar energy, Heat storage, Heat transfer

\footnotetext{
*Sorumlu yazar (Corresponding author): Mehmet KARAKILÇIK, kkilcik@cu.edu.tr
} 


\section{GíRiş}

Güneş enerjisi, kirletmeyen, tükenmeyen, en temiz ve sonsuz bir enerji kaynağıdır. Bu nedenle, alternatif temiz enerji kaynağı olarak güneş enerjisi gündemde önemli bir yer tutmaktadır. Güneş enerjisi ile çeşitli türden enerji (1s1, elektrik, hidrojen) üretilebilmektedir. Ancak, en önemli konulardan birisi bu üretimin verimli bir şekilde yapılabilmesidir. Bunun için, güneş enerjisi ile çalışan sistemlerin geliştirilmesi oldukça önemlidir. Günümüzde, birçok araştırmacı tarafından güneş enerjisi ile çalışan sistemler üzerinde çeşitli çalışmalar yapılmıştır. Bunlar; 1sitma, kurutma, saf su, buhar, elektrik ve hidrojen üretilmesinde güneş enerjisi ile çalışan sistemlerdir [1-4]. Bu sistemlerden birisi de güneş havuzlarıdır. Güneş havuzları gelen güneş enerjisinin yaklaşık \%20'sini düşük sıcaklıklarda 1sıl enerji biçiminde depolama bölgelerinde depolayabilen sistemlerdir [5]. Depolanan bu enerji, yılın her mevsiminde çekilebilmektedir. Depolama bölgesinden itibaren yüzeye yaklaşıldıkça havuz sıcaklığında bir azalma olduğu görülür. Güneş havuzları ile yapılan bir deneysel çalışmada ise, verimliliğin yaklaşık \%16 olduğu belirtilmiştir [6]. Güneş havuzlarında güneş ışının soğurulması, yansıması, saçılması, geçirilmesi, havuzun alt ve üst konveksiyonlu bölgelerinde konveksiyonla ve difüzyonla 1 sı ve tuz transferi gibi olaylar olmaktadır. Havuz yüzeyi ile atmosfer arasındaki ısı ve kütle transferi, rüzgar ve yağmur etkilerinin bilinmesi önemlidir. $\mathrm{Bu}$ konuda şimdiye kadar çeşitli çalışmalar yapılmıştır [7-14]. Bu etkilerin belirlenmesi kadar havuz yüzeyinden içeri giren güneş enerjisinin artırılması da büyük önem taşımaktadır. Güneş havuzlarının 1s1l performansının arttırılması ile ilgili önceki çalışmalarımızda havuza giren enerjinin artırılması ve havuzun üst yüzeyinden ve yan duvarlarından olan 1sıl kayıplarının en aza indirilmesinin önemli olduğu görüldü [15]. Güneş havuzları iç kısımları genellikle üç farklı bölgeden oluşmaktadır. Her bölgenin kalınlık ve yoğunlukları farklı özelliklere sahiptir. Bu yüzden, güneş havuzlarının 1S1 depolama performansını etkileyen birçok parametrenin incelenmesi gerekir.
$\mathrm{Bu}$ çalıșmada, depolama bölgesindeki ısının havaya kaçması önlemek için bu bölgenin üstüne bir tuz gradyentli (eğimli) bölge tasarlanmıștır. Bu bölge farklı yoğunluklarda tuzlu su tabakalarının üst üste yığılması ile oluşturulmuştur. Tabakaların saydam olması ve konveksiyonun bozulmaması için tabakalar en uygun kalınlıklarda ve yoğunluklarda seçilmeye çalışılmıştır. Bu parametrelerden özellikle havuzun iç bölgesini oluşturan tabakaların kalınlıkları ve yoğunluk dağılımlarındaki değişimin havuzun 1S1 performansı üzerindeki etkisi araştırılacaktır. Bunun için, tabaka kalınlıkları, yoğunluk ve sıcaklık dağılımları belirlenecektir. Elde edilecek ölçüm sonuçlarına göre de tabakaların öz 1s1 kapasitelerindeki değişiklikler belirlenecektir. Tabakaların öz 1S1 kapasiteleri ve tuzlulukları ampirik bağıntılar kullanılarak hesaplanacak ve havuzun iç bölgelerinin 1S1 performansı belirlenmeye çalışılacaktır.

\section{MATERYAL VE METOT}

\subsection{Materyal}

$\mathrm{Bu}$ çalışmada, yalıtımlı bir güneş havuzunun üst yüzeyine gelen güneş 1şınının güneş havuzunu oluşturan iç bölgelerde soğurulmasını ve isı olarak depolanması sağlamak için tuzlu su tabakalı bir güneş havuzu oluşturulmuştur. Burada amaç, tuzlu su tabakalarından geçerek depolanma bölgesine ulaşan ışınların depolama bölgesinde en verimli bir şekilde soğurulmasını ve burada 1S1 olarak depolanmasını sağlamaktır. Depolama bölgesinde depolanan ısının tutulması, yani iç bölgelerden havaya konveksiyonla 1sı transferini önlemek için depolama bölgesinin hemen üst k1smından itibaren yukarıya doğru azalan yoğunluklarda tabaklar üst üste yığılmak suretiyle 1sı yalıtımı görevi yapan bir konveksiyonsuz bölge oluşturulmuştur. Bu sayede, havuzun iç bölgesinde havaya, konveksiyonla is1 transferi önlenmeye çalışılmıştır. Depolama bölgesine ulaşan güneş 1şınının maksimum olması, yani daha fazla güneş ışığının havuza girmesini sağlamak için tabakalar temiz tutulmaya çalışılmıştır. Bu amaçla, daha fazla güneş ışı̆̆ının havuzun depolama bölgesine ulaşarak ısıya dönüşmesi sağlamak için en uygun tabaka kalınlıkları ve yoğunluk dağılımları belirlenmeye 
çalışılmıştır. Doğal olarak, havuza giren toplam güneş radyasyonu 1sıya dönüştürme oranlarının belirlenmesi için tabakaların öz 1s1 kapasitesi değerlerindeki değişimler ampirik bağıntılarla belirlenmeye çalışılmıştır. Bunun için farklı zamanlarda tabakaların tuz yoğunluğu dağılımlarını belirlemek için yoğunluk ölçümleri hidrometreler yardımıyla yapılmıştır. Tabakaların sıcaklık dağılımları ise saatlik olarak yapılmıştır. Böylece, havuzun iç bölgelerinin (üst konveksiyonlu, konveksiyonsuz ve düşük konveksiyonlu) yoğunluk ve sicaklık dağılımlarındaki değişimler ve depoladıkları 1sı oranları belirlenmeye çalışıllmıştır.

Şekil 1'de $150 \times 200 \mathrm{~cm}$ boyutlarında bir güneş havuzu görülmektedir. Havuzun iç kısmı üç farklı bölgeden oluşmaktadır. Bu bölgelerin yapıları ve işlevleri farklıdır. 1. Bölge; üst konveksiyonlu bölge (ÜKB) dir. Bu bölge havuz yüzeyini diş etmenlerden korumaktadır. Alt bölgelerdeki tabakalardan tuzun moleküler difüzyonla bu bölgeye ulaşması ile yoğunluğu zamanla bir miktar artabilir. Bakım gerektiren bir bölgedir ve zaman zaman temiz su ile değiştirilir. 2. Bölge; farklı yoğunluklu tuzlu su tabakalarından oluşan ara bölgedir. Yukarıdan aşağıya doğru artan yoğunluklarda olacak şekilde oluşturulmuştur. Konveksiyon akımları bu bölgede oluşmaz ve alt bölgeden üst bölgeye konveksiyonla 1S1 akışına engel olan bir 1sı yalıtım bölgesi (YB)'dir. Tuz eğimini oluşturan tabakaların yoğunluk dağılımları, tuz eğimini koruma sistemi yardımıyla tuzlu su ile beslenerek korunmaktadır. Bu sayede tabakalar tuz difüzyonuna karşı korunabilmektedir. 3. Bölge ise, alt konveksiyonlu bölgedir. Bu bölge çok yoğun tuzlu çözeltiden oluşturulmuş homojen bir bölgedir. $\mathrm{Bu}$ bölgenin her tarafında sıcaklık hemen hemen aynıdır. Güneş ışınları son olarak bu bölgeye ulaşır ve burada ısıya dönüşerek depolandığg1 1sı depolama bölgesidir. Güneş havuzu enerjisini güneşten gelen 1şınlardan almaktadır. Güneş 1şınları doğrusal olarak dağılmaktadır ve havuz yüzeyine yüzeyin normali $(\mathrm{N})$ ile $\mathrm{q}$ açısı yapacak şekilde gelir. Yüzeye gelen ışınlarının bir kısmı havuz yüzeyinden yansır, geri kalan kısmı ise önce üst konveksiyonlu bölgedeki (ÜKB) suyun kırılma indisine bağlı olarak kırılır ve soğurulur. Geri kalan kısmı konveksiyonsuz bölgeyi (YB) oluşturan tabakalar tarafinda kırılarak ve soğurularak taban bölgesi olan is1 depolama bölgesine (IDB) doğru ilerler. Is1 depolama bölgesine ulaşan 1şınlarda burada soğurulur ve 1s1 biçiminde depolanır. Şekil 1'de görüldüğü gibi, ÜKB 10 kalınlığında az yoğun tuzlu sudan oluşmaktadır. YB, her biri $10 \mathrm{~cm}$ kalınlığında ve yoğunluğu giderek artan 6 farklı tuzlu su tabakasından oluşmaktadır. IDB ise, $80 \mathrm{~cm}$ kalınlığında çok yoğun tuzlu su tabakasında oluşan konveksiyonlu bir bölgedir. Bu bölgede depolanan 1s1 hemen üst kisminda bulunan konveksiyonsuz tabakalar tarafında üst bölgeye kaçması engellenmektedir. Böylece, burada is1 uzun süre depolanabilmektedir.

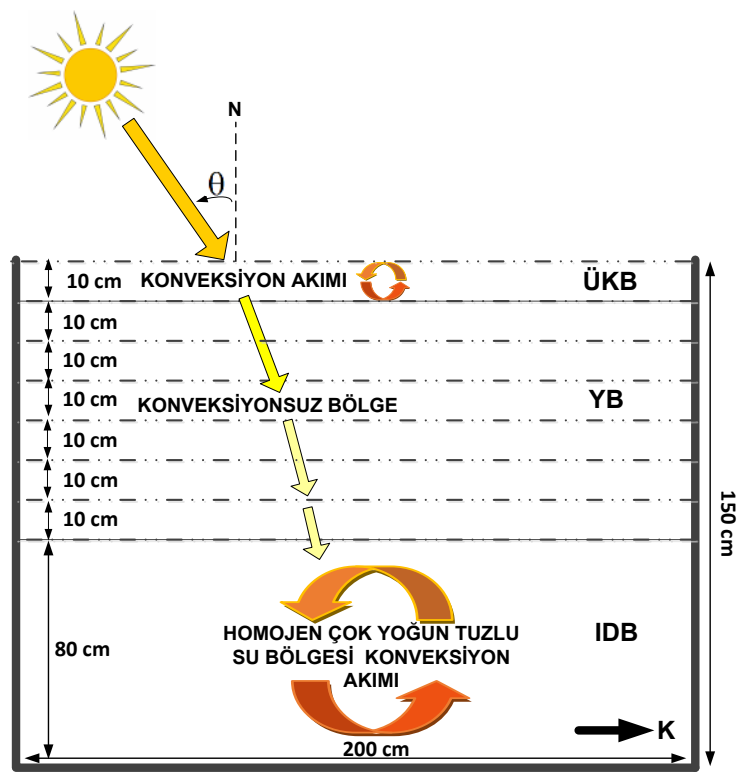

Şekil 1. Güneş havuzunun iç bölgelerinin yapısı

Şekil 1'de verilen güneş havuzunun iç bölgelerini oluşturan tuz su tabakalarının konumu, kalınlıkları ve konveksiyonlu bölgeler görülmektedir. $\mathrm{Bu}$ bölgelerin tuz su yoğunluğu, tuz eğimini koruma sistemi ile korunmaktadır. Ancak sıcaklık artışına ve azalışına bağlı olarak tuzun moleküler difüzyonundaki artışlar yüzünden tabakaların yoğunluklarında da bazı artış ve azalmalar olmaktadır. $\mathrm{Bu}$ nedenle, yıl içinde çok sicak aylarda özellikle çok yoğun tuzlu su tabakalarında artan difüzyonla oluşan bozulmalar yüzünden bazı 
aşağıdan yukarıya doğru olacak şekilde tabakalarda kütlesel değişimleri oluşmaktadır. Çizelge 1'de yılın en sıcak ayı olan Ağustos'ta tabakalardan oluşan bölgelerin yoğunluk değişimlerine bağlı olarak kütlesel değişimleri hesaplamıştır.

Çizelge 1. İç bölgeleri oluşturan tuzlu suyun Ağustos ayına ait kütlesel değişimi

\begin{tabular}{|l|c|c|c|c|}
\hline \multirow{2}{*}{ Bölge } & Kalınlık & Hacim & Yoğunluk & Kütle \\
\cline { 2 - 5 } & $l(\mathrm{~m})$ & $V\left(\mathrm{~m}^{3}\right)$ & $\rho\left(\mathrm{kg} / \mathrm{m}^{3}\right)$ & $m(\mathrm{~kg})$ \\
\hline ÜKB & 0,10 & 0,4 & 1023,71 & 163,79 \\
\hline YB & 0,60 & 2,4 & 1073,21 & 2578,10 \\
\hline IDB & 0,80 & 3,2 & 1178,46 & 3771,07 \\
\hline
\end{tabular}

\subsection{Isı Depolaması}

Güneş havuzu yüzeyine gelen güneş enerjisinin önemli bir kısmı tabakalar tarafından soğurulmakta ve 1sıya dönüşerek orada bir süre tutulmaktadır. Tabakaların 1sıl performansı, havuz içindeki konumuna ve yapısal özelliklerine bağlıdır. Bunlar: havayla teması, çevreyle 1sı yalıtımı durumu, kalınlıkları, sıcaklıkları, 1s1 iletim ve 1s1 kapasitesi, yoğunlukları, tuz eğimi ve konveksiyon durumuna bağlı olarak değişmektedir. Bu yüzden, tabakaların özelliklerinin iyi bilinmesi gerekmektedir. Bunlar iyi bilinirse, güneş havuzunun isi depolama kapasitesi ve performans1 hesaplanabilir.

Üst konveksiyonlu bölgede 1S1 depolaması: Üst konvektif bölgeye gelen güneş 1şınlarının bir kısmının burada soğurulmasıyla, bu bölgenin sıcaklığı bir miktar artmaktadır. Aynı zamanda, bu bölgenin hemen altındaki daha sicak bölge olan konveksiyonsuz bölgeden de iletim yolu ile 1s1 akışı olmaktadır. Dolayısıyla, bu bölgeden her ne kadar havaya olan 1sı kayıpları çok olsa da yine de az bir miktar 1s1 depolaması yapabilmektedir. Ancak, burada tutulan 1sının havuzun 1S1 performansı üzerinde çok önemli bir katkısı bulunmamaktadır. Aksine havayla teması dolayısıyla iletimle olan 1sı kaybının büyük bir kısmı burada olmaktadır. Bu çalışmada, ÜKB' in sıcaklık ve yoğunluk ölçümleri yapılmış ve aşağıdaki eşitliklere göre de hesaplanmıştır. ÜKB'de depolanan 1s1,
$\mathrm{Q}_{\mathrm{st}, \mathrm{ÜKB}}=\mathrm{m}_{\mathrm{ÜKB}} \mathrm{C}_{\mathrm{p}, \ddot{U} \mathrm{UKB}}\left[\mathrm{T}_{\ddot{U K B}}-\mathrm{T}_{\mathrm{h}}\right]$

Eşitlik (1)'de verilen denklem ile bulunur. Burada, $m_{\ddot{U} K B}$ tabakanın toplam kütlesidir. $C_{p, \ddot{U} K B}$ ÜKB'in öz 1s1 kapasitesi $\left(\mathrm{J} / \mathrm{kg}^{\circ} \mathrm{C}\right), T_{\ddot{U K B}}$ tabakanın sıcaklığ 1 $\left({ }^{\circ} \mathrm{C}\right)$ ve $T_{h}$ ise havuzu çevreleyen havanın sıcaklığıdır ve Ocak, Mayıs ve Ağustos ayı için sirasiyla, ortalama $9^{\circ} \mathrm{C}, 18^{\circ} \mathrm{C}$ ve $28^{\circ} \mathrm{C}$ olarak alınmıştır. ÜKB'deki az tuzlu çözeltinin kütlesi,

$m_{\ddot{U K B}}=\rho_{\ddot{\mathrm{UKB}}} \mathrm{V}_{\ddot{\mathrm{UKB}}}$

Eşitlik (2) ile hesaplanır. Burada, $\rho_{\ddot{U} K B}$; ÜKB'in ortalama yoğunluğudur $\left(\mathrm{kg} / \mathrm{m}^{3}\right) . V_{U ̈ K B}$ ise, bölgenin toplam hacmidir $\left(\mathrm{m}^{3}\right)$ ve değeri $0,4 \mathrm{~m}^{3}$ dür. $\mathrm{Az}$ yoğun tuzlu su tabakas1 olan ÜKB'in öz 1s1 kapasitesi,

$\mathrm{C}_{\mathrm{p}, \mathrm{ÜKB}}=4180-4,396 \mathrm{~s}_{\mathrm{ÜKB}}+0,0048 \mathrm{~s}_{\mathrm{ÜKB}}^{2}$

ampirik bağıntısı ile bulunur. Burada $s_{\ddot{U} K B}$, ÜKB'in tuzluluğudur (g/kg).

$\mathrm{S}_{\mathrm{ÜKB}}=\frac{\rho_{\mathrm{ÜKB}}-988+0,4\left[\mathrm{~T}_{\text {ÜKB}}-20\right]}{0,65}$

eşitliği ile hesaplanmaktadır [6]. ÜKB'in 1s1 depolama kapasitesinin, eşitlik (1) ile doğru bir şekilde hesaplanabilmesi için, Eşitlik (3) ile bölgenin sıcaklık ve yoğunluk değișimine bağlı olarak öz 1sı kapasitelerinin doğru hesaplanması gerekmektedir. Benzer şekilde, bu eşitlikler havuzun diğer bölgeleri olan YB ve IDB için de yazılabilir.

Konveksiyonsuz bölgede 1s1 depolaması: Üst konvektif bölgede (ÜKB) soğurulduktan sonra konveksiyonsuz bölgeye (YB) gelen güneş ışınlarının bir kısmının burada soğurulmasıyla, bu bölgeyi oluşturan tabakaların sıcaklıkları yukarıdan aşağıya doğru artmaktadır. Aynı zamanda, bu bölgenin hemen altındaki daha sicak bölge olan 1s1 depolama bölgesinden bu bölgeye iletim yolu ile ısı akışı olmaktadır. Dolayısıyla, bu bölgeden iletimle ÜKB'ye olan 1sı kayıplarına rağmen yine de tabakalarda yukarıdan aşağıya doğru artan bir şekilde önemli miktarlarda 1S1 tutulmaktadır. $\mathrm{Bu}$ artış, YB'deki tuz eğimine benzer şekilde bir sıcaklık gradyenti biçimindedir. 
Burada tutulan 1sının havuzun 1S1 performans1 üzerinde önemli katkısı bulunmaktadır. Bu çalışmada, YB'in sıcaklık ve yoğunluk ölçümleri yapılmıştır. Bu değerlere göre, tabakaların toplam kütlesi, öz 1sı dağılımları hesaplanmıştır. YB'de depolanan 1s1;

$\mathrm{Q}_{\mathrm{st}, \mathrm{YB}}=\mathrm{m}_{\mathrm{YB}} \mathrm{C}_{\mathrm{p}, \mathrm{YB}}\left[\mathrm{T}_{\mathrm{YB}}-\mathrm{T}_{\mathrm{h}}\right]$

eşitliğine göre bulunur. Burada, $m_{Y B}$ tabakanın toplam kütlesidir. $C_{p, Y B}$ tabakanın öz 1sı kapasitesi, $T_{Y B}$ tabakaların sıcaklığıdır. YB'nin kütlesi;

$m_{Y B}=\rho_{Y B} V_{Y B}$

eşitliği ile hesaplanmaktadır. Burada, $\rho_{Y B}$; YB' in ortalama yoğunluğudur. $V_{Y B}$ ise, bölgenin toplam hacmidir ve değeri $2,4 \mathrm{~m}^{3}$ 'dür. Az yoğun tuzlu su tabakası olan YB'in öz 1sı kapasitesi ise,

$\mathrm{C}_{\mathrm{p}, \mathrm{IDB}}=4180-4,396 \mathrm{~s}_{\mathrm{YB}}+0,0048 \mathrm{~s}_{\mathrm{YB}}^{2}$

Burada $s_{Y B}$, ÜKB' in tuzluluğudur $(\mathrm{g} / \mathrm{kg})$.

$\mathrm{S}_{\mathrm{YB}}=\frac{\rho_{\mathrm{YB}}-988+0,4\left[\mathrm{~T}_{\mathrm{YB}}-20\right]}{0,65}$

denklemi ile hesaplanmaktadır. Bu denkleme göre, öz 1S1 kapasiteleri bölgeyi oluşturan tabakaların yoğunluk ve sıcaklık dağılımlarına göre değişmektedir.

Alt konveksiyonlu bölgede 1sı depolaması: ÜKB'den havuza giren güneş 1şınları, YB'de soğurulduktan sonra geri kalan kismı 1sı depolama (IDB) ulaşır ve burada soğurulur ve 1sı biçiminde depolanır. $\mathrm{Bu}$ bölge konveksiyonlu bir bölge olduğu için, 1sı dağılımı hemen hemen homojendir. Ancak, IDB'i çevreleyen yan duvarlar ve YB ile temasın olduğu kısımlarda iletimle az bir miktarda 1sı akışı olmaktadır. Bu bölgelerdeki 1sı kayıpları, sıcaklık dağılımı eğimine göre hesaplanmaktadır. Burada tutulan 1sinın havuzun is1 performans1 üzerinde önemli katkısı bulunmaktadır. Bu çalışmada, IDB'nin sıcaklık ve yoğunluk dağılımı ölçümleri yapılmıştır. $\mathrm{Bu}$ değerlere göre, tabakaların toplam kütlesi, öz 1S1 dağılımları hesaplanmıştır. $\mathrm{Bu}$ hesaplara göre de, IDB'de depolanan 1S1,
$\mathrm{Q}_{\mathrm{st}, \mathrm{IDB}}=\mathrm{m}_{\mathrm{IDB}} \mathrm{C}_{\mathrm{p}, \mathrm{IDB}}\left[\mathrm{T}_{\mathrm{IDB}}-\mathrm{T}_{\mathrm{h}}\right]$

denklemine göre bulunur. Burada, $m_{I D B}$ tabakanın toplam kütlesidir. $C_{p, I D B}$ tabakanın öz 1sı kapasitesi, $T_{I D B}$ tabakanın sıcaklığıdır. IDB'in toplam kütlesi ise,

$\mathrm{m}_{\mathrm{IDB}}=\rho_{\mathrm{IDB}} \mathrm{V}_{\mathrm{IDB}}$

eşitliği ile gösterilir. Burada, $\rho_{I D B}$; IDB' in ortalama yoğunluğudur. $V_{I D B}$ ise, bölgenin toplam hacmidir ve değeri $3,2 \mathrm{~m}^{3}$ dür. Çok yoğun tuzlu su tabakası olan IDB'in öz 1sı kapasitesi ise,

$\mathrm{C}_{\mathrm{p}, \mathrm{IDB}}=4180-4,396 \mathrm{~s}_{\mathrm{IDB}}+0,0048 \mathrm{~s}_{\mathrm{IDB}}^{2}$

$s_{I D B}$ ise, IDB' in tuzluluğudur $(\mathrm{g} / \mathrm{kg})$.

$\mathrm{S}_{\mathrm{IDB}}=\frac{\rho_{\mathrm{IDB}}-988+0,4\left[\mathrm{~T}_{\mathrm{IDB}}-20\right]}{0,65}$

denklemi yardımıyla hesaplanmaktadır.

\section{BULGULARI VE TARTIŞMA}

Güneş havuzunun enerji kaynağı güneş enerjisidir ve birim yüzey alanına düşen güneş enerjisi oranı önemlidir. Havuz yüzeyine Güneşten gelen ışınlar, havuzun iç bölgesini oluşturan tuzlu su tabakaları tarafindan kademe kademe soğurularak havuzun en önemli bölgesi olan 1s1 depolama bölgesine (IDB) ulaşmaktadır. Bu bölgeye ulaşan güneş 1şınları soğurularak 1sıya dönüşmektedir. Bu enerji dönüşüm işlemi havuzun iç bölgelerinin oluşturan tabakaların yapısına göre değişmektedir. Güneş ışınlarının özellikle IDB'de soğurulan kısmı 1s1 biçiminde depolanabilmekte ve daha uzun süre burada tutulmaktadır. $\mathrm{Bu}$ bölgenin üstündeki yalıtım bölgesinde (YB) daha az 1sının tutulabildiği ve YB'den itibaren ÜKB'ye kadar sıcaklığın azaldığı görülmüştür. $\mathrm{Bu}$ azalmalar tabakaların yapısına göre değişir. $\mathrm{Bu}$ bakımdan güneş havuzunun yapısı önemlidir.

Güneş havuzun iç ve dış bölgelerinin yapısı güneş havuzunun 1sı depolama performansı üzerinde önemli etkiye sahiptir. $\mathrm{Bu}$ yüzden, bu bölgelerin yapısı ile ilgili parametrelerin iyi bilinmesi 
gerekmektedir. Özellikle, iç bölgeleri oluşturan tuzlu su tabakalarının kalınlıklarının, termofiziksel ve kimyasal özelliklerinin iyi bilinmesi gerekmektedir. Bunlardan özellikle tuzlu suyun tuz yoğunluğu, öz 1sısı ve iletkenliği iç bölgelerin 1S1 performansı üzerinde etki eden önemli parametrelerdir. $\mathrm{Bu}$ parametreler, sistem performansının belirlenmesinde önemli etkiye sahiptir. Şekil 1'de havuzunun iç bölgeleri, tuzlu su tabakalarının kalınlıkları ve yoğunluk dağılımları verilmektedir. Şekilde verilen güneş havuzunun sistem performansını havuz yüzeyine gelen güneş ışınının tabakalar tarafında bir kısmı soğurulmakta geri kalan kısmı ise alt tabakalar geçirilmektedir. Tabaklarda soğurulan ışınlar, tabakaların öz 1S1 kapasitesi, 1s1 iletim katsayısı, iletimle 1sı transferi gibi özelliklerde olumlu ya da olumsuz olarak etkilenmektedir. Bu neden, güneș havuzunu etkileyen bu parametrelerin sistemin 1sıl performansı üzerindeki etkisi belirlenmeye çalışılmıştır.

Güneş havuzun iç bölgelerine bulunduğu yerin iklimsel şartlarına ve coğrafi konumuna bağlı olarak farklı zamanlarda farklı oranlarda güneş enerjisi gelmektedir. Gelen güneş enerjisi havuzu oluşturan tabakalar tarafindan soğurulmakta ve isı biçiminde depolanabilmektedir. Dolayısıyla, Tabakaların sıcaklık dağılımları farklı zamanlarda farklı değerlere ulaşmaktadır.

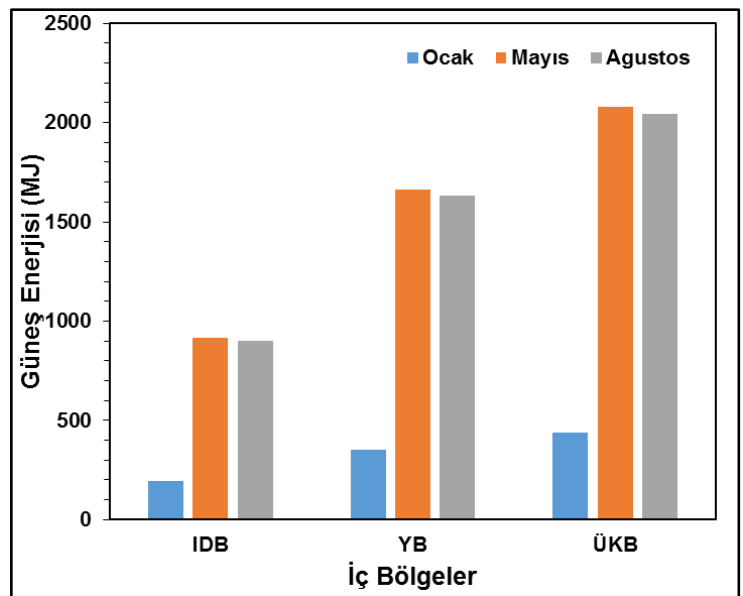

Şekil 2. Havuz yüzeyine gelen güneş enerjisi dağılımı
Şekil 2'de güneş havuzunun iç bölgelerini oluşturan ÜKB, YB ve IDB'nin yüzeyine düşen toplam güneş enerjisi dağılımı Ocak, Mayıs ve Ağustos ayı için verilmiştir.

En fazla güneş enerjisi en üst yüzey olan ÜKB'ye düşmüştür. Gelen güneş enerjisi tabakaların derinliğine, soğurma ve geçirgenlik özelliklerine göre ÜKB'den aşağıya doğru azalarak IDB'e ulaşmıştır. Beklenildiği gibi, güneş enerjisi en düşük Ocak ve en yüksek ise Mayıs-Ağustos ayında olduğu görülmüştür.

Şekil 3'de model bir güneş havuzunun iç bölgelerinin Ocak, Mayıs ve Ağustos ayları için aylık ortalama sıcaklık dağılımları görülmektedir. Havuz yüzeyine gelen güneş enerjisine bağlı olarak, küçük boyutlu ve yalıtımlı bir güneş havuzunun iç bölgelerinin Ocak, Mayıs ve Ağustos ayları için aylık ortalama sıcaklık dağılımları verilmiştir.

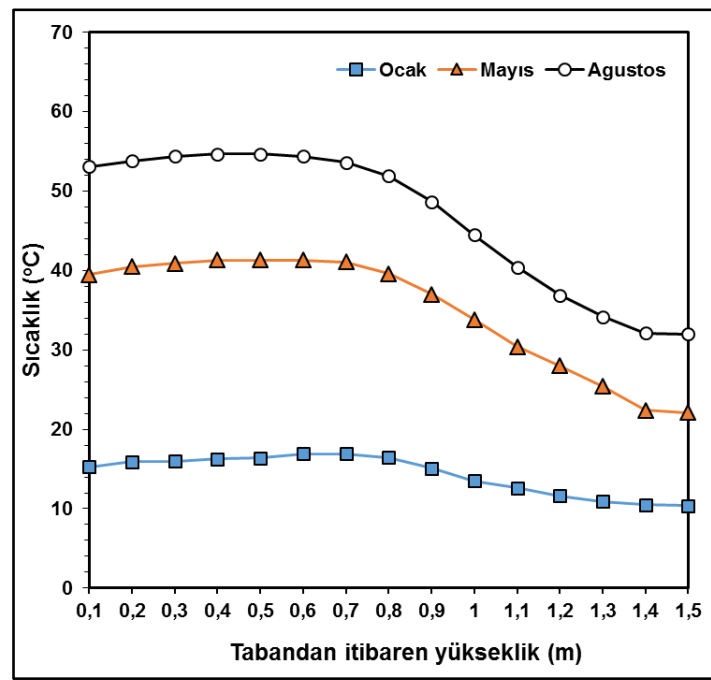

Şekil 3. Güneş havuzunun iç bölgelerinin sıcaklık dağılımı

Şekil 3'de görüldüğü gibi, 1sı depolama bölgesinin sıcaklığı Ağustos ayında en yüksek değerlere ulaşmıştır. Güneş havuzun en alt bölgesindeki sıcaklık dağılımı tabandan itibaren 0,7 m'ye kadar hemen hemen aynı değerdedir. Çünkü bu bölge konveksiyonlu bir bölgedir ve 151 dağıılımı IDB'de 
yaklaşık homojendir. Ağustos'ta sıcaklık IDB'de yaklaşık $53^{\circ} \mathrm{C}$ ile en yüksek değerlere ulaşırken, $0,7 \mathrm{~m}$ 'den itibaren $0,8 \mathrm{~m}$ arasında bir kavis yaparak azalmaya başlamıştır. $\mathrm{Bu}$ noktadan itibaren oluşan tuz eğimi ile birlikte aynı zamanda bir sıcaklık eğimi de oluşmaya başlamıştır. 0,8 cm'den 1,4 m'e kadar olan 1sı yalıtım bölgesi (YB) denen tuz eğimli bölge aynı zamanda bir sıcaklık eğimi oluşmasını sağlamaktadır. Isı yalıtım bölgesinde oluşan bu sicaklık eğimi $50^{\circ} \mathrm{C}, 47^{\circ} \mathrm{C}$, $40^{\circ} \mathrm{C}, 35^{\circ} \mathrm{C}, 28^{\circ} \mathrm{C}, 23^{\circ} \mathrm{C}$ şeklinde azalmaktadır. Isı depolama bölgesi (IDB)'in sıcaklığı Mayıs ayında yaklaşık olarak $45^{\circ} \mathrm{C}$ iken tuz eğimli bölgede ise $35^{\circ} \mathrm{C}, 30^{\circ} \mathrm{C}, 27^{\circ} \mathrm{C}, 19^{\circ} \mathrm{C}$ olarak kademe kademe azaldığı görülmektedir. Aynı şekilde Ocak ayı için IDB' in yaklaşık sıcaklığg1 15 iken, YB'in sıcaklığ ise kademe kademe azalmaktadır. Sicaklığın Ağustos ayında en yüksek değerle çıkmakta, fakat Ocak ayında ise en düşük değerlere inmektedir. İç bölgelerdeki sıcaklık artışı ve azalması üzerinde başta bölgenin iklimsel değişimlerin önemli bir rol üslenmektedir. Ancak, uygun kalınlık ve yoğunluklarda bu değerle olumlu olarak geliştirmek mümkündür.

Şekil 4'te, Ocak, Mayıs ve Ağustos aylarında iç bölgelerin yoğunluklarının tabandan itibaren yükseklikle değişimi görülmektedir. Havuzun tabanından itibaren 0,7 m'ye kadar yoğunluk oranlarında gözle görülür bir azalma olduğu görülmektedir. $\mathrm{Bu}$ azalmanın en önemli nedeni, homojen tuzlu su yoğunluğuna sahip ve eğimsiz bir bölge olan IDB'nin sıcaklığındaki artışla birlikte tuz difüzyonunda da bir artışa neden olduğu görülmektedir. Bu IDB'nin yoğunluk dağılımında tabandan yukarıya doğru az bir miktar azalmaya neden olmaktadır. Tuz moleküllerinin difüzyonla birlikte üst kısımlara doğru taşınması özellikle YB'de bir yoğunluk artışına neden olmuştur. YB'de tuz eğimin mevsimsel değişimlerden etkilendiği görülmektedir. $\mathrm{Bu}$ değişimler tuz eğimi dişardan yoğun tuzlu su ile beslenerek yeniden onarılabilmektedir.

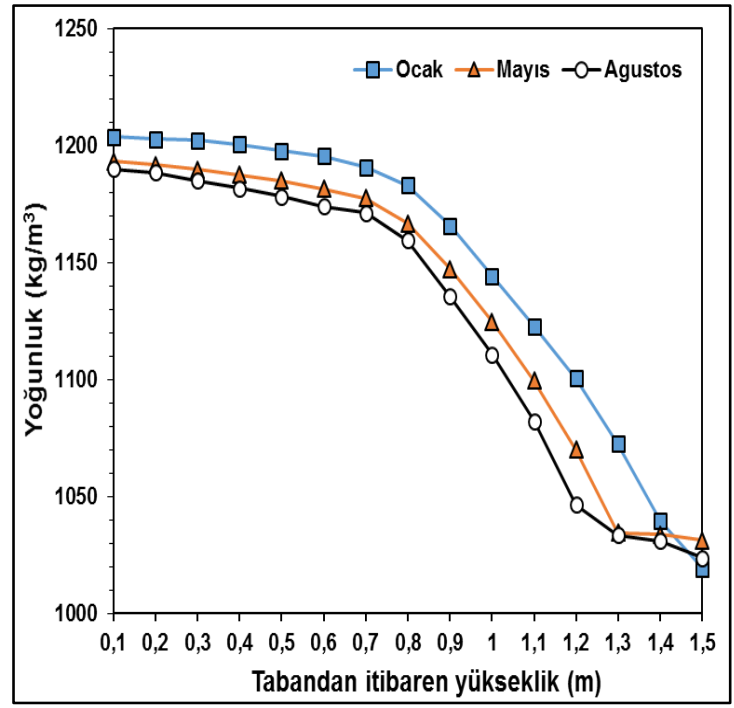

Şekil 4. Güneş havuzu yoğunluğu dağılımı

Çizelge 2. İç bölgelerin ortalama öz 1sı kapasiteleri

\begin{tabular}{|l|c|c|c|c|c|c|c|c|c|}
\hline \multirow{2}{*}{ Aylar } & \multicolumn{3}{|c|}{ Sicakl1k $\left({ }^{\circ} \mathrm{C}\right)$} & \multicolumn{3}{c|}{ Yoğunluk $\left(\mathrm{kg} / \mathrm{m}^{3}\right)$} & \multicolumn{3}{c|}{ Öz 1S1 $\left(\mathrm{J} / \mathrm{kg}^{\circ} \mathrm{C}\right)$} \\
\cline { 2 - 10 } & $T_{\ddot{U} K B}$ & $T_{Y B}$ & $T_{I D B}$ & $\rho_{\ddot{U} K B}$ & $\rho_{Y B}$ & $\rho_{I D B}$ & $C_{p, U ̈ K B}$ & $C_{p, Y B}$ & $C_{p, I D B}$ \\
\hline Ocak & 10,4 & 12,36 & 16,26 & 1019,20 & 1107,50 & 1197 & 4066,01 & 3588,82 & 3287,47 \\
\hline Mayıs & 23,3 & 29,66 & 40,68 & 1031,33 & 1084,97 & 1184,10 & 3959,27 & 3659,39 & 3294,65 \\
\hline A ğustos & 32 & 39,46 & 53,82 & 1023,71 & 1073,21 & 1178,46 & 3984,20 & 3696,92 & 3295,55 \\
\hline
\end{tabular}

Şekil 5 'te ise, güneş havuzunun iç bölgelerinin öz 1sı kapasite değerlerinin mevsimsel değişimleri görülmektedir. Eşitlik 3, 7, 11 kullanılarak, Ocak, Mayıs ve Ağustos ayları iç bölgelerin öz 1s1 kapasiteleri hesaplanmıştır. Yoğunluk dağılımlarının öz 1Sı kapasitesi üzerinde önemli bir etkiye sahip olduğu görülmektedir. Özellikle, en yüksek yoğunluğa sahip depolama bölgesinde, 
sıcaklığın etkisi yok denecek kadar azdır. Ancak yoğunluk burada çok etkilidir.

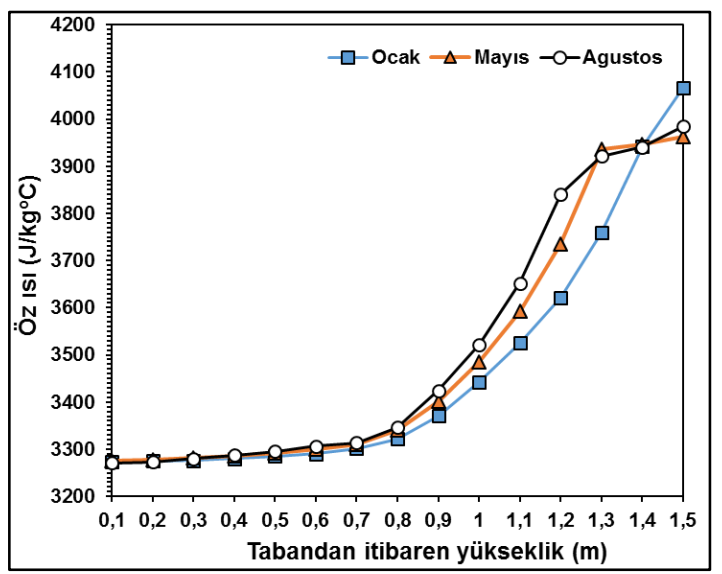

Şekil 5. Güneş havuzunun iç bölgelerinin öz 1S1 dağılımı

Havuzun iç bölgelerinin öz 1sı kapasitelerinin ortalama değerleri Ocak, Mayıs ve Ağustos ayları için hesaplanmıştır. IDB'nin öz 1s1 kapasitesi yaklaşık olarak 3287,91, 3295,42 ve $3296,62 \mathrm{~J} / \mathrm{kg}^{\circ} \mathrm{C}^{\prime}$ dir. YB'in öz $1 \mathrm{~s} 1$ kapasiteleri $3610,05,3682,57$ ve $3716,90 \mathrm{~J} / \mathrm{kg}^{\circ} \mathrm{C}^{\prime}$ dir. ÜKB'de ise, yoğunluk dağılımları ile birlikte sıcaklık dağılımlarının da etkisi görülmektedir. ÜKB'nin öz 1S1 kapasitesi, Ocak ayında $4066 \mathrm{~J} / \mathrm{kg}^{\circ} \mathrm{C}$ iken Mayıs ve Ağustos aylarında ise 3962,15 ve $3984,20 \mathrm{~J} / \mathrm{kg}^{\circ} \mathrm{C}$ olarak hesaplanmıştır.

Güneş havuzunun iç bölgelerini oluşturan tuzlu su tabakalarının zamanla değişen sıcaklık ve yoğunluk dağılımları ölçülmüştür. Elde edilen bu ölçüm değerlerine göre de, sıcaklık ve yoğunluk dağılım profilleri çıkarılmıştır (Şekil 3 ve 4). Bu ölçüm değerlerinin her bölge için ortalamaları alınmak suretiyle ÜKB, YB ve IDB'nin ortalama sıcaklık, yoğunluk ve öz 1sı değerleri elde edilmiştir (Çizelge 2).

Çizelge 2'deki veriler göre, havuzun iç bölgelerde depolanan 1sı oranları Eşitlik 1-5-9 kullanılarak hesaplanmıştır. Elde edilen oranlar Ocak, Mayıs ve Ağustos ayları için hesaplanmıştır (Şekil 6). Güneş havuzunun iç bölgelerinde mevsimsel değişimle birlikte 1sı depolama oranlarında önemli değişimler görülmektedir. Şekil 2'ye göre en fazla güneş enerjisi ÜKB'e gelmesine rağmen, Şekil 6'da görüldüğü gibi en az 1 sıl enerji ÜKB'de tutulabilmektedir. Mayıs ve Ağustos aylarında güneş enerjisindeki artışla birlikte hızlı bir şekilde çok az miktarda 1sı tutabilmiştir.

Şekil 2'de görüldüğü gibi, Ocak, Mayıs ve Ağustos ayları için, IDB, YB ve ÜKB'in 1s1 depolama kapasiteleri belirlenmiştir. Buna göre, IDB'de depolanan 1sı, Ocak ayında en düşüktür ve 11,42 MJ'dir. Ağustos ayında ise en yüksek 320,94 MJ değerine ulaşmıştır. Şekil 6'da is1 depolama özelliğinin en yüksek olduğu bölge IDB olup, YB'den itibaren ÜKB'e kadar azaldığı ve ÜKB'de önemli düzeyde 1sı depolamanın mümkün olmadığı görülmektedir. Ocak ayında çevre sıcaklığındaki ani düşüşler yüzünden özellikle ÜKB'de hemen hemen hiç 1S1 depolanamazken, çevre sıcaklığındaki artışla birlikte Mayıs ve Ağustos aylarında bir miktar 1sı depolanabildiği görülmüştür.

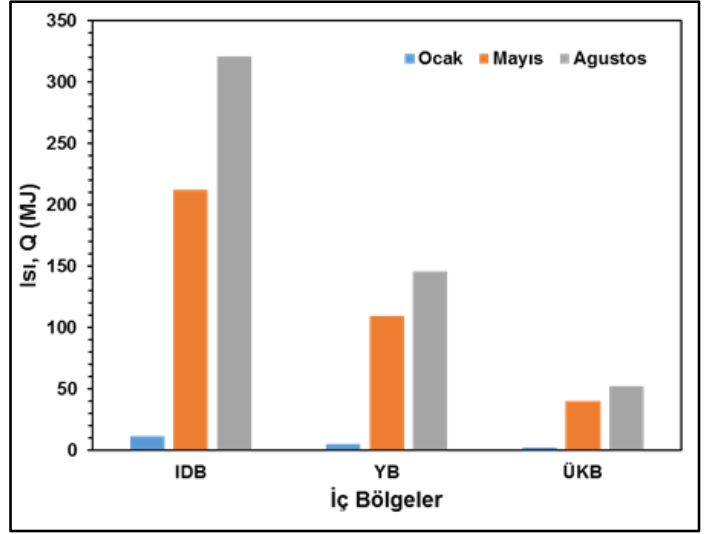

Şekil 6. Farklı aylarda güneş havuzunun iç bölgelerinde depolanan toplam 1sı oranları

ÜKB'de tutulan 1sının havuzun 1S1 performans1 üzerine önemli bir katkısı yoktur. Fakat ara bölge olan YB'deki 1sı artışları önemlidir ve bu bölge aynı zamanda bir yalıtım görevi yapmaktadır ve IDB'in $1 \mathrm{~S} 1$ performansını etkilemektedir. $\mathrm{Bu}$ yüzden YB, IDB'den ÜKB'ye iletimle olan 1s1 kayıplarının azalmasında önemli bir ara bölgedir ve havuzun 1sıl performansı üzerine çok önemli katkısı olduğu görülmüştür. 


\section{SONUÇLAR VE ÖNERILLER}

Güneş havuzlarında en önemli konularda birisi 1sı performansının arttırılmasıdır. Bunun için iç bölgelerinin yapısı çok önemlidir. Özellikle, tuz gradyentli (eğimli) bölge olan ve yalıtım bölgesi de (YB) denen ara bölgenin tabandan üst bölgeye (IDB'den ÜKB'ye) doğru konveksiyonla 1S1 akımlarını önlediği görülmüştür. Bu bölge, güneş ışınlarının sadece 1S1 depolama bölgesine ulaşmasına yardım etmediği aynı zamanda ısının 1S1 depolama bölgesinde uzun süre tutulmasında yardımcı olan önemli bir bölgedir. Böylece, havuz yüzeyine gelen ışınlarının önemli oranda tuzlu su tabakaların bulunduğu YB ve IDB tarafinda soğurularak 1sıya dönüştürüldüğü ve uzun süre depolanabildiği görülmüştür. Ancak, bu iki bölgenin tuz yoğunluğundaki artışla birlikte öz 1S1 kapasitesinin azaldığg görülmüştür. Bu azalmayla birlikte güneş havuzunun 1sı depolama performansı da olumsuz bir etkilemiştir. Bu da havuzun isı performansının azalmasına neden olmuştur. $\mathrm{Bu}$ azalmayla birlikte, YB'de depolanan 1s1 miktarı da düşmüştür. YB'deki bu düşüş, aynı zamanda IDB'de depolanan 1s1 miktarını olumsuz bir şeklide etkileyerek havuzda depolanan isı miktarının azalmasına ve dolayısıyla havuzun isı performansının da düşmesini sağlamıştır. Sonuç olarak, özellikle tuz gradyentli bölgeyi oluşturan tabakaların kalınlık ve yoğunluklarının güneş havuzunun 1sı performansı üzerinde çok önemli etkisi olduğu görülmüştür. Geliştirilecek yeni model güneş havuzu sistemleri sayesinde, güneş havuzlarının 1sıl performanslarının artırılabileceği ve daha verimli bir güneş enerjisi sistemi haline dönüşebileceği kanaatindeyiz.

\section{TEŞEKKÜR}

Bu çalışma FBE 96.1, FEF 96.1 ve FBA-20143195 nolu projeler kapsamında hazırlanmıştır. Katkılarından dolayı Çukurova Üniversitesi Bilimsel Araştırmalar Projeleri Birimine teşekkür ederiz.

\section{KAYNAKLAR}

1. Styris, DL., Harling, OK., Zaworski, RJ., Leshuk, J., 1976. The Nonconvecting Solar Pond Applied to Building and Process Heating, Solar Energy, 18; 3, 245-251.

2. Bozkurt, I., Karakilcik, M., 2015. The Effect of Sunny Area Ratios on the Thermal Performance of Solar Ponds, Energy Conversion and Management, 91; 323-332.

3. Ding, L.C., Akbarzadeh, A., Date, A., 2016. Transient Model to Predict the Performance of Thermoelectric Generators Coupled with Solar Pond. Energy, 103; 271-289.

4. Erden, M., Karakilcik, M., Dincer, I., 2016. Performance Investigation of Hydrogen Production by the Flat-Plate Collectors Assisted by a Solar Pond, International Journal of Hydrogen Energy (In Press, Corrected Proof.) doi:10.1016/j.ijhydene.2016.04.116.

5. Karakilcik, M., Dincer I., Rosen, MA., 2006. Performance Investigation of a Solar Pond, Applied Thermal Engineering, 26; 7, 727-735.

6. Wang, Y.F., Akbarzadeh, A., 1982. A Study of the Transient Behaviour of Solar Ponds. Solar Energy, 7; 12, 1005-1017.

7. Hawlader, M.N.A., 1980. The Influence of the Extinction Coefficient on the Effectiveness of Solar Ponds. Solar Energy, 25; 461-464.

8. Alcaraz, A., Valderrama, C., Cortina, JL., Akbarzadeh, A., 2016. Enhancing the Efficiency of Solar Pond Heat Extraction by Using Both Lateral and Bottom Heat Exchangers. Solar Energy, 134; 82-94.

9. Bansal, PK., Kaushik, ND., 1981. Salt Gradient Stabilized Solar Pond Collector. Energy Conversion and Management, 21; 81-95.

10. Akbarzadeh, A., MacDonald R.W.G., 1982. Introduction of a Passive Method for Salt Replenishment in the Operation of Solar Ponds. Solar Energy, 29; 1, 71-76.

11. Wang, Y.F., Akbarzadeh, A., 1983. A Parametric Study on Solar Ponds, Solar Energy, 30; 6, 555-562.

12. Akbarzadeh, A., 1984. Effect of Sloping Walls on Salt Concentration Profile in a Solar Pond. Solar Energy, 33; 2, 137-141. 
13. Cengel, YA., Özıș1k, M.N., 1984. Solar Radiation Absorption in Solar Ponds, Solar Energy, 33; 6, 581-591.

14. Beniwal, S., Singh, R., Saxena, N.S., Bhandari, R.C., 1987. Thermal Behaviour of Salt Gradient Solar Ponds. J. Phys. D: Appl. Phys., 20; 1067-1071.

15. Karakılçı, M., 1998. Yalıtımlı Prototip Bir Güneș Havuzunun Performansının Saptanması, Çukurova Üniversitesi Fen Bilimleri Enstitüsü, Doktora Tezi, Adana. 